\title{
Assessing the Quality of Educational Websites in Sudan using Quality Model Criteria through an Electronic Tool
}

\author{
Asim Seedahmed Ali Osman \\ College of Computer Science and Engineering \\ University of Hafr Al Batin, Hafar Al Batin, Saudi Arabia
}

\begin{abstract}
The application of internet has grown in recent years. Due to this, there is an increase in the number of websites which creates diversity in the services. This leads the researchers to do more research in the quality of websites in order to set standards and models to maintain its quality. The main objective of these standards is to support the trust and speed which is the cornerstone which are the basis for using websites. Various statistics reports show that the sites of institutions and companies which applied the quality standards have achieved high rates in terms of the user satisfaction and the number of visitors. This study has incorporates the concept of website and electronic gates, its objectives, advantages, types and in addition to its quality and standards of e-websites. It also touched on previous studies conducted on website in the world, the Arab world and African peninsula and also in the Sudan in support of the development of Sudanese websites. The proposed models consist of important metrics to evaluate the application, quality of content, aesthetic aspects, multimedia, reputation and security etc. This paper also proposed an application for evaluating the quality of websites based. This model is applied on Sudanese websites such as governmental, educational, and commercial etc. The authors used the object oriented programing approach to build the proposed model using the PHP language with the combination of CSS and Java script.
\end{abstract}

Keywords-Website quality; e-websites; education; information technology; PHP language

\section{INTRODUCTION}

Information Technology plays an important and tangible role in our scientific life. Many institutions have adopted the use of it and are considered as a mediator in the learning and communication process in universities. This improves and develops the product of education and its implementation for various programs or sites. This also helps the students to join these educational institutions. In this paper, a new methodology is proposed to evaluate the various educational website in different universities present inside the Sudan.

The educational website of various universities contains different entities such as the main pages of various site, the glimpse about the respective university, its vision, mission, various colleges and its departments etc [1]. It also consists of main page of the course, information about the course, information about the faculty members who are working in the particular college, the announcements and video meetings, topics related to homework, study materials and activities, course content and electronic reference list, information about virtual classes, events done in the conference rooms and the explanations about synchronous and asynchronously communication etc.

The universities faced various problems during the instance of providing the important components of website, especially at the process of evaluating the educational websites of Sudanese universities at the international level [3]. The evaluation process may be carried out low often due to the lack of control and failure to considering some requirements of quality. This is due to the non-application of international quality standards such as (ISO),(OSI) [4] which are the set of internationally recognized technical specifications used for the purpose of evaluating the websites. It can be done in order to operate the production and commodity processes, models, performance and management, which includes the esthetically aspects etc. Content Quality Standard is done in the search engine, information guide, maps and automatic updating for site where, the site also requires a standard Multimedia which is represented by video, audio and motion systems which make the site more attractive, smoother interaction, smoother in clarify the content etc.

The main aim of this research it is study the analysis part of the various Sudanese educational websites [4] using different quality standards for the purpose of assessing the quality of educational sites and along with its services. This paper also indents to develop a comprehensive framework model which contains all the main quality elements and accompanying indicators for accessing a quality of website discussed in previous researches. Based on the previous researches, we proposed this paper to achieve the following goals:

- To define of quality standards for educational website.

- To define the standards and quality models for educational websites.

- To apply various standards of quality to Sudanese educational websites.

- To disseminate and support the Sudanese e-government and to perform its services with high efficiency and interactivity. 
- To propose a model for evaluating the quality of educational websites based on appropriate standards and measurements for determining its quality.

- To improving the work environment and to change the quality of performance of Sudanese educational websites.

- To improving the confidence of customers using these educational websites.

- To make decisions based on real information from educational websites.

- To create websites in an integrated way to develop the product of education.

In order to achieve these goals, it is necessary to design a form for evaluating the educational websites [7] by knowing the performance quality of these educational websites of Sudanese universities. The form allows the entry of an educational website URL for the university and the evaluation is carried out by the user and the system administrator by clicking the evaluation button. The site is evaluated based on the calculations and equations of the quality criteria that have been mentioned. It shows the evaluation result and the outcome of each websites evaluation in addition to a graph showing values of criteria. There are also details about the reports of evaluation when selecting evaluation details of websites.

Remainder of the paper is summarized as follows. Section 2 depicts the review of various methods for accessing the quality of normal websites and also the educational websites. Section 3 provides an attribute of the proposed methodology with its functional architecture and its working principle. Section 4 explains the various criteria for evaluating the quality of website along with its working principle and various formulas. Section 5 proposes the evaluation results for various university websites present in the Sudan. Section 6 shows the conclusion of this paper.

\section{LITERATURE REVIEW}

Recently, the internet has created a new environment enabling any organization to conduct its entire set of processes and practices of business especially through online [1]. Elearning and its associated activities is any process performed via an Internet-based, computer-mediated network [2]. There are many categories of e-learning which tend to be used interchangeably leading to policy incoherence. Majority of these learning practices were done by the application of Websites.

Web based artifacts have been developed over the past few years. The increasing acceptability of websites increases the challenges, for instance, in knowing or assessing where we are standing regarding the quality of product, and how it can be improved [3]. However, there is still no methodology which is widely recognized as quantitative process for the evaluation of quality of websites. One of the main goals in the evaluation of website is qualitative and comparison based process. This is done in order to understand the entire process which a set of quality characteristics and attributes etc. Various methods have been proposed by earlier researchers [4-10, 20] in this process.

Authors in [11] proposed a quantitative evaluation approach to assess the websites quality called Website Quality Evaluation Method (QEM). This approach might be useful to evaluate and compare characteristics quality and attributes of a Web product lifecycle in different phases. Particularly, the authors evaluated their proposed methodology in six academic websites sites. At the end of the evaluation process, a ranking is obtained for each selected site. Specifically, the evaluation process generates elemental, partial, and global indicators or quality preferences that can be easily analyzed, backward and forward traced, justified, and efficiently employed in decisionmaking activities.

Educational websites are analyzed in different perspectives. Authors in [12] developed a theoretical based framework for evaluating the quality of website from the perspective of user satisfaction. Other researchers concentrated on some specific features of websites such as authors in [13] developed a framework to measure the importance of usability of websites, while authors in [14] investigated and evaluated the design of university websites. Other researchers, while assessing the websites of universities considered various other features. Authors in [15] designed criteria to evaluate the resources of websites for maximum utilization of the scholarly context and research within the area of the art and history. Authors in [16, 19] tried to find solutions to problems among the user and involved evaluating various university websites inside the South African based on certain factors.

Author in [2] emphasized the learning practices by the application of various websites. Authors in [1] stress the importance of E-learning and its associated activities through the intern and on-line based applications. Website Quality Evaluation was done by [11] where, the characteristics quality and attributes of a Web product lifecycle in different phases were evaluated and compared. It can also be used in the decision making activities. User satisfaction is considered by authors in [12]. They proposed a theoretical based framework for evaluating the quality of website based on the user satisfaction. Usability of websites was considered and a framework was developed for it by authors [13]. Their framework also empathizes to define the standards and quality models for various educational websites. The main drawback behind their framework is applied only for the educational websites. Authors in [16, 19] found various solutions to problems among the user of various university websites inside the South African based on certain factors. Main drawbacks of their works is it is applies only inside the South African University websites.

\section{PROPOSED Methodology}

Authors developed a standard which depends on various ISO based Quality model for assessing the quality of educational websites. It is divided into six levels based on their different purposes and topics. It is further directed to evaluate the sites particularly belongs to the Sudanese educational institutions. Various criteria proposed in [18] were applied in the proposed model. The proposed quality model 
shown in Fig. 1 includes various metrics which represents the frameworks for determining the quality of the educational website in terms of its content, structure and presentation. These metrics are as follows:

- Aesthetics

- Ease of Use

- Rich Contents

- Multimedia

- Reputation

- Security

\section{A. Aesthetics}

Aesthetic aspects of an element maintain a fundamental importance in evaluating the quality of websites since, it leaves a positive impact for the visitor of the educational website. It works on by monitoring the interaction between the user and the educational website. It also monitors some aspects of the Human-Computer-Interaction (HCI) [17] branch and also by the incentives to interact with the site such as availability which includes:

- Image: $40 \%$.

- Colors taken $20 \%$.

- Tables and text, backgrounds, etc.

- Resolution and standard Table takes $40 \%$.

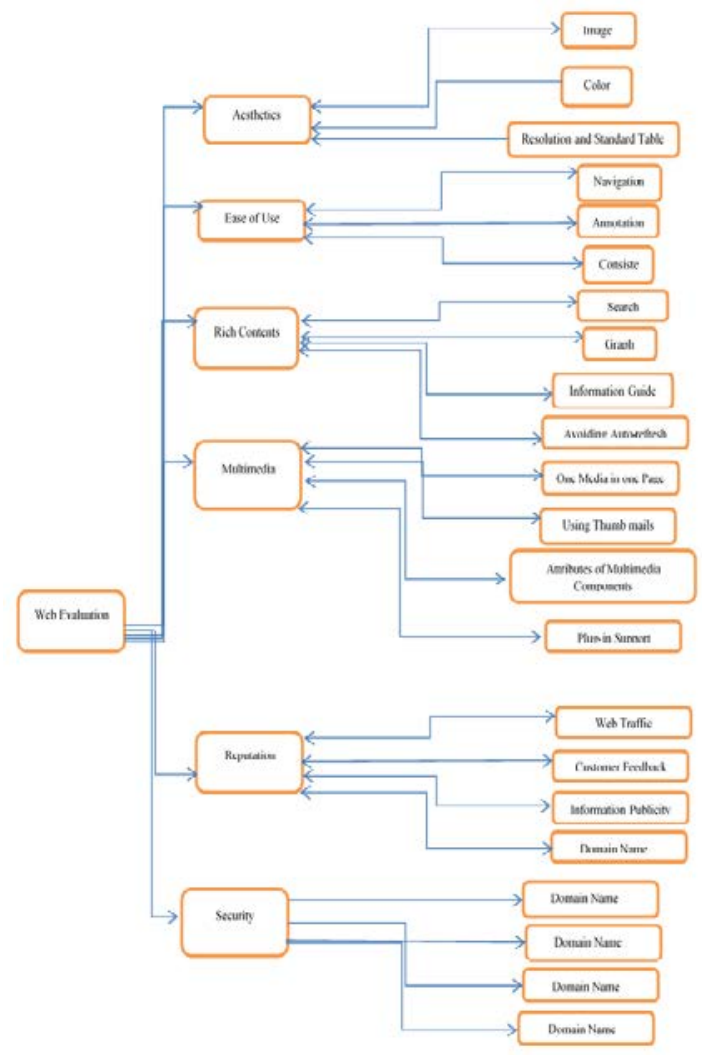

Fig. 1. Various Criteria of the Proposed Model.
The aesthetics scale is calculated based on the following equation:

Aesthetics =images $* 0.4+$ tands $* 0.2+$ color $* 0.2+$ underline $* 0.2$

\section{B. Ease of Use}

One of the most important problems in the factor for ease of use is the measurement of Usability is for websites or for the products of software etc. Various criteria or models have been proposed earlier for measuring and assessing the usability within societies interacting between human being and the software engineering based societies.

This metric contains of various sub-metrics like:

- The Navigation offer consists of $30 \%$.

- Annotation alerts and routers consist of $30 \%$.

- CSS consists of $40 \%$.

The scale for ease of use is calculated based on the following formula:

Ease of Use $=\operatorname{cssl}^{*} 0.4+$ nav $^{*} 0.3+$ ann $* 0.3$

\section{Rich Contents}

The quality of the website contents can be described by the availability of various elements such as:

- Search Engine, which takes 20\%.

- Graphs, which takes 30\%.

- The Information Guide, which takes 30\%.

- Avoiding Auto-refresh, which takes 20\%.

Other elements that make the website more responsive to the requests of visitors and users fall under the content quality scale. It can be calculated based on the following formula.

Rich Contents=

bulletin*0.3+guide*0.3+searchenginge*0.2+autorefresh*0.2

\section{Multimedia}

Multimedia represents the video and audio elements, movement systems etc. When these elements were used inside the site, it will make the website more attractive, interactive and smoother in terms of working. The multimedia elements such as sound and image can be appropriate as content of the site. This can be as follows:

- $\quad$ One Media in one Page takes 30\%.

- Using thumb mails takes $30 \%$.

- Attributes of multimedia and its components take $10 \%$.

- $\quad$ Plug-in support takes 30\%.

The vision differs from the aesthetic aspects and ease of use of application. The multimedia scale is calculated based on the following formula:

Multimedia $=$

plugin $* 0.3+$ thumbnail $* 0.3+$ attribute $* 0.1+$ minone $* 0.3$ 


\section{E. Reputation}

The reputation of a website defines the extension of reliability of it and the extent of interaction which is accepted by the environment for which it is directed or by the local, regional or international bodies. These are accredited to measure the quality of the websites which covers the following:

- Web Traffic efficiency takes 30\%.

- Customer Feedback takes 30\%.

- Information and Publicity takes 20\%.

- Domain Name takes $20 \%$.

The reputation scale is calculated based on the following formula:

Reputation $=$

$0.3 *$ feedback $+0.2 *$ domain $+0.3 *$ trafic $+0.2 *$ publicity

\section{F. Security}

Information security plays an important role in the protection of assets of an institution. We often hear about security incidents of information security, such as site distortion, server piracy, and data leakage etc. Hence, there is an urgent need to devote more resources to protecting information assets. It is as follows:

- The login mechanism takes $40 \%$.

- $\quad$ The firewall takes $30 \%$.

- User display levels and usage of session variables when interacting with the site takes 30\%.

The security scale is calculated based on the following formula

Security $=0.3 *$ firewall $+0.3 *$ sesion $+0.4 * \operatorname{login}$

\section{IMPLEMENTATION OF THE EVALUATION REPORT SCREEN}

Following are the various outputs of evaluation reports done in different types of Sudanese educational websites. Implementation of the evaluation details screen is shown in Fig. 2 which is one of the implementation result of the proposed system.
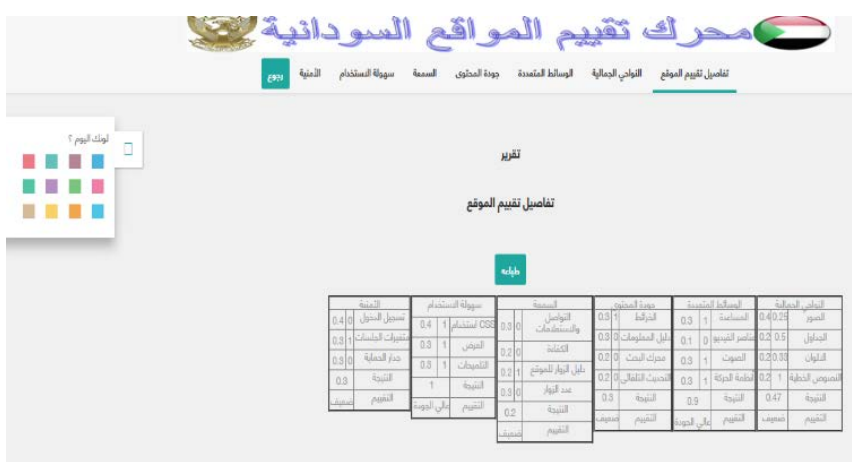

Fig. 2. Implementation of the Evaluation Details Screen.
The above figure depicts the implemented image of the evaluation details screen with all the details of the evaluation of the website, details of all standards such as aesthetics and multimedia, quality of content, reputation, ease of use and security etc.

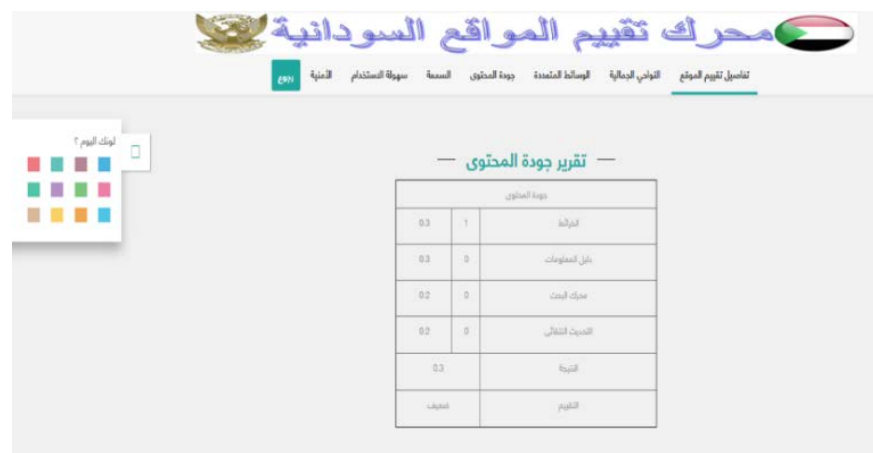

Fig. 3. Implementation Screen of the Content Quality Details.

Fig. 3 shows the implementation of the content quality and the details screen. It has various criteria for measuring the quality of the content in addition to the value of the criterion in the evaluation of result of the actual website.

\section{EVALUATION RESUltS OF VARIOUS EDUCATIONAL WEBSITES}

The proposed system is tested for the various Sudanese educational websites. The following diagrams represent the evaluation results of the various educational websites. Fig. 4 evaluation results of (www.neelain.sd), Fig. 5 evaluation results of (www.sustech.edu), Fig. 6 evaluation results of (www.uofk.edu), Fig. 7 evaluation results of (www. uofg.edu.sd), Fig. 8 evaluation results of (www.aau.edu.sd), Fig. 9 evaluation results of (www.siu-sd.com), Fig. 10 evaluation results of (www.bahri.edu.sd), Fig. 11 evaluation results of (www.iau.edu.sa), Fig. 12 evaluation results of (www.oiu.edu.sa), Fig. 13 evaluation results of (www.mu.edu.sd), Fig. 14 evaluation results of (www.ush.sd) and Fig. 15 evaluation results of (www.ribat.edu.sd).

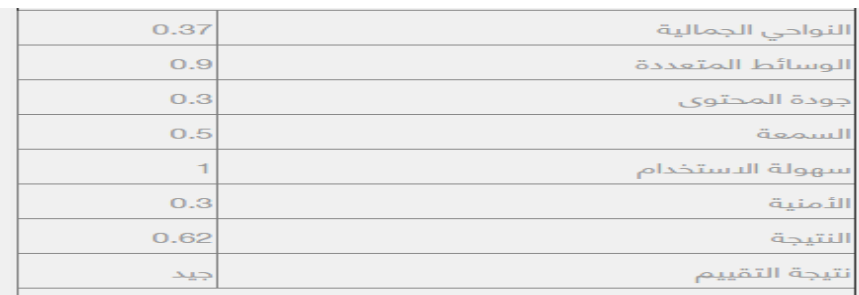

Fig. 4. www.neelain.edu.sd.

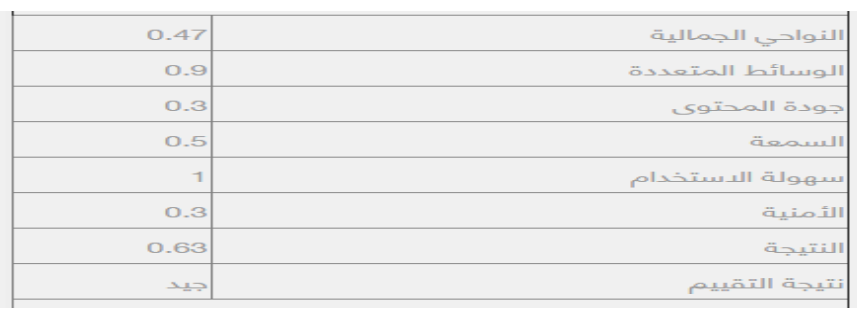

Fig. 5. www.sustech.edu. 


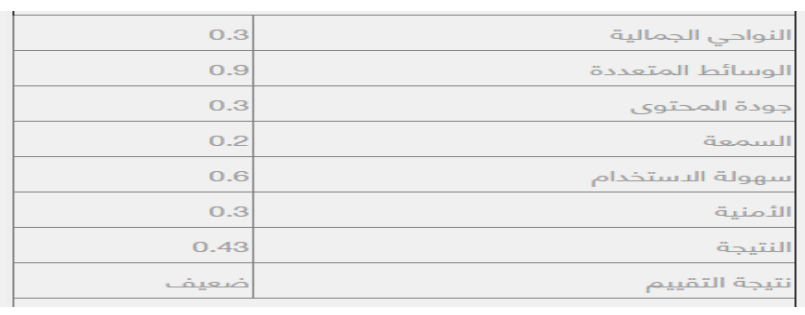

Fig. 6. www.uofk.edu.

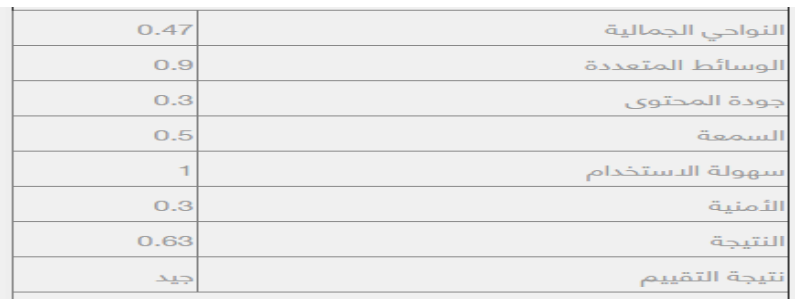

Fig. 7. www. uofg.edu.sd.

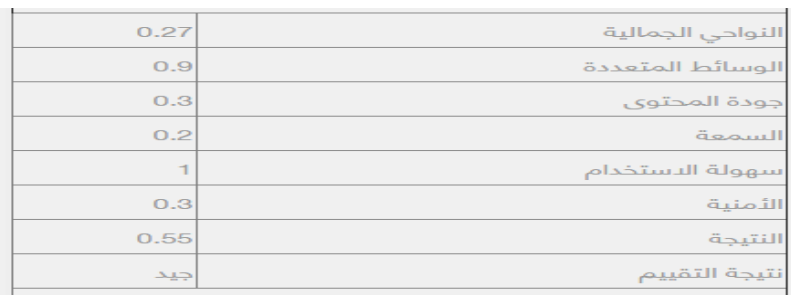

Fig. 8. www.aau.edu.sd.

\begin{tabular}{|c|c|}
\hline 0.37 & النواحي الجمالية \\
\hline 0.9 & الوسائط المتعددة \\
\hline 0.3 & جودة المحتوى \\
\hline 0.2 & السمعة \\
\hline 1 & سهولة الدستخدام \\
\hline 0.3 & الأمنية \\
\hline 0.56 & النتيجة \\
\hline |جيد & نتيجة التقييم \\
\hline
\end{tabular}

Fig. 9. www.siu-sd.com.

\begin{tabular}{|c|c|}
\hline 0.37 & النواحي الجمالية \\
\hline 0.9 & الوسائط المتعددة \\
\hline 0.3 & جودة المحتوى \\
\hline 0.5 & |السمعة |ل| |ل| \\
\hline 1 & سهولة الـستخدام \\
\hline 0.7 & |الأمنية \\
\hline 0.7 & |النتيجة \\
\hline |جيد جدا & |نتيجة التقييم \\
\hline
\end{tabular}

Fig. 10. www.bahri.edu.sd.

\begin{tabular}{|c|c|}
\hline 0.37 & النواحي الجمالية \\
\hline 0.9 & الوسائط المتعددة \\
\hline 0.5 & جودة المحتوى \\
\hline 0.2 & |السمعة \\
\hline 0.6 & سهولة الدستخدام \\
\hline 0.3 & الأمنية \\
\hline 0.46 & النتيجة \\
\hline |ضعيف & نتيجة التقييم \\
\hline
\end{tabular}

Fig. 11. www.iua.edu.sa.

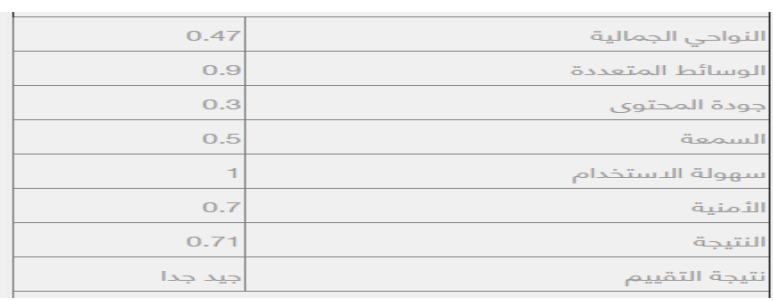

Fig. 12. www.oiu.edu.sa.

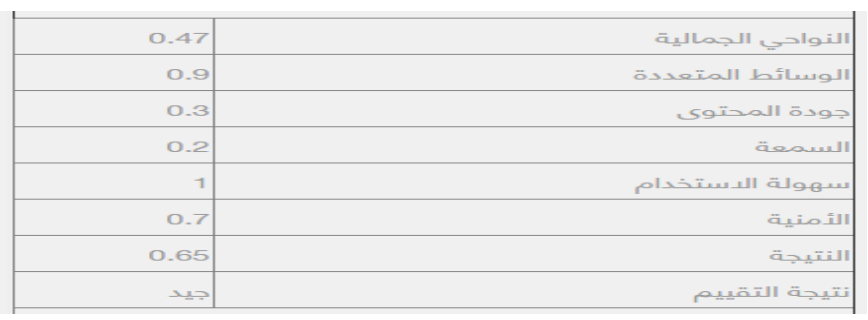

Fig. 13. www.mu.edu.sd.

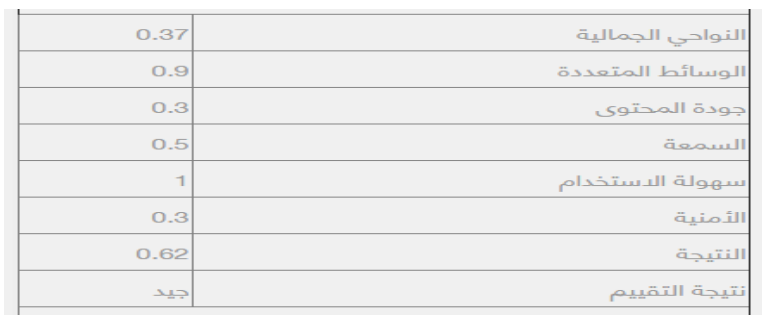

Fig. 14. www.ush.sd.

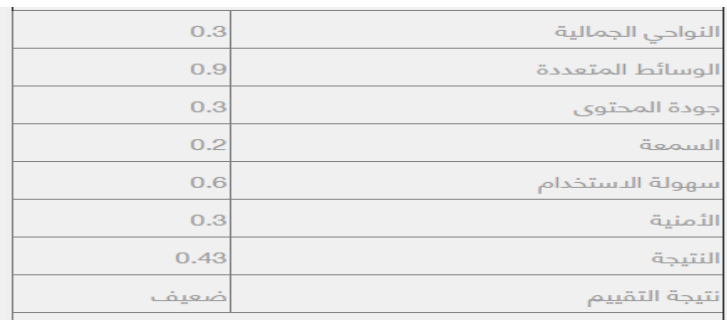

Fig. 15. www.ribat.edu.sd.

The final evaluation of educational websites is calculated based on the following formula:

E.W $=0.1 *$ tot_aesthetic $+0.3 *$ tot_easeofuse $+0.1 *$ tot_multimedia +0 $.1 *$ tot_richcontent $+0.2 *$ tot_reputation $+0.2 *$ tot_security.

- The scale of aesthetics, obtained from the sum of its sub-elements, takes the $10 \%$.

- The measure of ease of use resulting from the sum of its sub-elements takes the $30 \%$.

- The quality measure of the content generated from the sub-component takes a total of $10 \%$.

- The resulting multimedia scale takes the $10 \%$ of its subgroups.

- The reputation scale obtained from the sum of its subelements is $20 \%$.

- The resulting security measure takes $20 \%$ of the subcomponent totals. 
Table I depicts the Sudanese educational sites and its various evaluation results based on the proposed model. In this method, the authors took a sample of the Sudanese educational websites and evaluated them and put them in the form. The numbers that express the number of websites, for ease of presentation, the comparison and the analysis. This comparison is done after analyzing it through the following table. This will lead us to reach the various deficiencies in the educational sites in order to take care of them and then to address them.

TABLE I. SUDANESE EDUCATIONAL SitES AND EVALUATION RESUlTS

\begin{tabular}{|l|l|}
\hline Evaluation & Website \\
\hline 62 & www.neelain.edu.sd \\
\hline 63 & www.sustech.edu \\
\hline 43 & www.uofk.edu \\
\hline 63 & www.uofg.edu.sd \\
\hline 55 & www.aau.edu.sd \\
\hline 56 & www.siu-sd.com \\
\hline 70 & www.bahri.edu.sd \\
\hline 46 & www.iua.edu.sd \\
\hline 71 & www.oiu.edu.sd \\
\hline 65 & www.mu.edu.sd \\
\hline 62 & www.ush.sd \\
\hline 43 & www.ribat.edu.sd \\
\hline $85.25 \%$ & Average of Evaluation \\
\hline
\end{tabular}

\section{CONCLUSION AND FUTURE ENHANCEMENTS}

The Internet has shown a rapid growth in terms of education which led to a new definition of almost all aspects of teaching. The Internet created a new teaching environment far different from anything that has come before. The explosion of the web has determined the need of measurement criteria to evaluate the aspects related to the quality of educational websites. Awareness of issues in quality issues has affected every websites in recent years, since an educational organization with a website is difficult to use and interact with gives a poor image on the Internet and weakens the position of it. Hence, it is important for a website especially the educational website to assess the quality of its eservice, in order to improve its quality. This paper proposes general criteria for evaluating the quality of Sudanese educational website in various evaluation criteria such as Aesthetics, Ease of Use, Rich Contents, Multimedia, Reputation and Security are depicted in detail long with its formulas. These criteria can be used by web site developers and its designers to create and to maintain the quality of educational websites do that the electronic service can be easily improved.

\section{REFERENCES}

[1] World Best Website Awards. (2007). Quality criteria for website excellence world best website awards. [online]. Available from http://www.worldbest.com/criteria.htm [2013, July 5].

[2] Khlaisang, J. (2010). Proposed Models of Appropriate Website and Courseware for E-Learning in Higher Education: Research Based
Design Models. Proceedings of the E-LEARN 2010 - World Conference on E-Learning in Corporate, Government, Healthcare \& Higher Education organized by the Association for the Advancement of Computing in Education, Orlando, Florida, October 18-22, 2010.

[3] Khlaisang, J. (2012). Analysis of the Cultural Factors Affecting the Proper Design of Website and Electronic Courseware for e-Learning in ASEAN. Proceedings of the 26th Annual Conference of Asian Association of Open Universities (AAOU ( , 2012 Chiba, Japan, October 16-18, 2012.

[4] Suliman Zakaria Suliman Abdall, Quality Assurance in Sudanese Higher Education: Current Status and Challenges Ahead, Journal of Total Quality Management, Vol 17, No. 1, 2016.

[5] Vera Silva Carlos, Ricardo Gouveia Rodrigues,Web site quality evaluation in Higher Education Institutions, Procedia Technology, Vol 5, pp.273-282, 2012.

[6] Michaelis, P., Ziesemer, T. Minimum quality standards and benchmarking in differentiated duopoly. JER (2020). https://doi.org/10.1007/s42973-020-00050-y.

[7] Jesse R. Sparks, Peter W. van Rijn \& Paul Deane (2021) Assessing Source Evaluation Skills of Middle School Students Using Learning Progressions, Educational Assessment, 26:4, 213-240,

[8] Layla Hasan, Emad Abuelrub, Assessing the quality of web sites, Applied Computing and Informatics, Volume 9, Issue 1, pp. 11-29, 2011

[9] Sattler, C., \& Sonntag, K. (2018). Quality cultures in higher education institutions-development of the Quality Culture Inventory. In P. Meusburger, M. Heffernan, \& L. Suarsana (Eds.), Geographies of the university (pp. 313-327). Cham: Springer International Publishing.

[10] Rahnuma, N. Evolution of quality culture in an HEI: critical insights from university staff in Bangladesh. Educ Asse Eval Acc 32, 53-81 (2020).

[11] Luis Ospina ,Daniela Godoy,Guillermo Lafuente Gustavo Rossi, "Assessing the quality of academic websites: a case study", New review in Hypermedia and multimedia, pp 81-103, 2010.

[12] Zhang, P., Dran, G. 2001. Expectations and ranking of website quality features: results of two studies on user perceptions. In: Proceedings of the 34th Hawaii International Conference on System Sciences.

[13] Lautenbach, M.A.E., Schegget, I.S., Schoute, A.M., Witteman, C.L.M. 2006. Evaluating the Usability of Web Pages: A Case Study. Available at: http://www.phil.uu.nl/preprints/ckipreprints/PREPRINTS/ preprint011.pdf.

[14] Yoo, S., Jin, J., 2004. Evaluation of the home page of the top 100 university web sites. Academy of Information and Management Sciences 8 (2), 57-69.

[15] Osborne, C., Rinalducci, J. 2002. Evaluation of Web Based Resources within the Art History Discipline, Technical Report, University of North Carolina.

[16] Singh, I., Sook, A. 2002. An evaluation of the usability of South African university web sites. In: Proceedings of the 2002 CITTE Conference, Durban, South Africa.

[17] Wang, E.S.T. (2016), “The moderating role of consumer characteristics in the relationship between website quality and perceived usefulness", International Journal of Retail and Distribution Management, Vol. 44 No. 6, pp. 627-639.

[18] Wiranata, A.T. and Hananto, A. (2020), “Do website quality, fashion consciousness, and sales promotion increase impulse buying behavior of e-commerce buyers?”, Indonesian Journal of Business and Entrepreneurship, Vol. 6 No. 1, p. 74.

[19] Longstreet, P., Brooks, S., Featherman, M. and Loiacono, E. (2021), "Evaluating website quality: which decision criteria do consumers use to evaluate website quality?", Information Technology \& People, Vol. ahead-of-print No. ahead-of-print. https://doi.org/10.1108/ITP-05-20200328.

[20] Loukas K. Tsironis, Educational websites quality assessment framework, International Journal of Decision Sciences, Risk and Management 2021 10:1-2, 51-77. 